\title{
Use of seawater and discard salts of caliche industry to improve the copper extraction from leaching process
}

\author{
Pia Hernández, Ph. D. Engineering of Mineral Processes ${ }^{1}$, Monserrat Martinez, M. Sc. Engineering of Mineral Processes ${ }^{1}$
}

1'Universidad de Antofagasta, Chile, pia.hernandez@uantof.cl, monserrat.martinez.vergara@ua.cl

\begin{abstract}
The objective of this research is to study the acidnitrate-chloride system in the chalcopyrite leaching process $\left(\mathrm{CuFeS}_{2}\right)$ in order to propose a hydrometallurgical process that allows the use of salts or discarding solutions from the caliche industry as well as saline discard solutions (such as the rejection solution of the reverse osmosis process) or raw seawater. The methodology used is to use low grade ore, concentrate and pure chalcopyrite samples which are conditioned and leached by stirring, varying concentrations of chloride, solvent, source of nitrate and pretreatment. The system has shown good copper extraction results at atmospheric pressure, over 60\% and up to 90\%. Salts and discard solutions have been used and it has been proven that they could be alternatives of raw materials in the process. A conditioning stage is essential to accelerate the dissolution kinetics of copper in the systems studied.
\end{abstract}

Keywords-Seawater, chalcopyrite, chloride, nitrate, leaching.

\section{INTRODUCTION}

The northern of Chile is characterized by having reserves of metallic minerals such as copper and nonmetals such as caliche [1]. In addition, the weather is desert therefore water is a scarce resource. It is necessary to consider that copper oxides are increasingly scarce due to the exploitation of the deposits. This in the future will cause hydrometallurgical plants to stop being used. The sulfide minerals to be increasingly predominant in mining companies. An alternative solution would be hydrometallurgical treatment of sulfur species, such as chalcopyrite $\left(\mathrm{CuFeS}_{2}\right)$. It is known from the literature that chalcopyrite tends to be refractory to leaching in sulfate media [2]. This does not occur in chloride media [3] and especially in oxidizing media [4]. Several authors have studied the use of nitrogen species for leaching sulfur minerals such as nitric acid [5], nitrate [6, 7], nitrite [8], among others. Due to the caliche industry, present in the northern part of Chile, it is expected that salts or discarding solutions from this industry are expected to be used for leaching chalcopyrite. In addition, the chlorinated medium could be supplied by seawater or brines.

The objective of the research is to study the acid-nitratechloride system in the chalcopyrite leaching process $\left(\mathrm{CuFeS}_{2}\right)$ in order to propose a hydrometallurgical process in the future, which allows the use of salts or discarding solutions of the caliche industry as well as saline discard solutions (such as the rejection solution of the reverse osmosis process).

\section{METHODOLOGY}

\section{A. Ore}

Digital Object Identifier (DOI):

http://dx.doi.org/10.18687/LACCEI2020.1.1.449

ISBN: 978-958-52071-4-1 ISSN: 2414-6390
Different chalcopyrite samples from Antofagasta and Atacama Regions of Chile were used (Table I). The samples were low grade ore $(1.6 \% \mathrm{Cu})$, concentrate $(12.9 \% \mathrm{Cu})$ and pure samples $(29.1 \% \mathrm{Cu})$. The mineralogical species were obtained by optical microscopy, semi-quantitative X-ray diffraction and the chemical composition was determined by atomic absorption spectrometry (AAS). Different particle sizes were used according to the methodology determined.

TABLE I

MINERALOGICAL CHARACTERIZATION OF SAMPLES USED IN THE TESTS

\begin{tabular}{|c|c|c|c|c|}
\hline \multirow{2}{*}{ Minerals } & \multirow{2}{*}{ Formula } & Low copper grade & Concentrate & Pure sample \\
\cline { 3 - 5 } & & \multicolumn{3}{|c|}{ Amount (\%) } \\
\hline Chalcopyrite & $\mathrm{CuFeS}_{2}$ & 4.8 & 37.2 & 85.2 \\
\hline Covellite & $\mathrm{CuS}$ & 0.0 & 12.5 & 0.0 \\
\hline Digenite & $\mathrm{Cu}_{9} \mathrm{~S}_{5}$ & 0.0 & 2.9 & 0.0 \\
\hline Pyrite & $\mathrm{FeS}_{2}$ & 8.1 & 34.0 & 2.1 \\
\hline Magnetite & $\mathrm{Fe}_{3} \mathrm{O}_{4}$ & 36.7 & 0.0 & 0.0 \\
\hline \multicolumn{2}{|c|}{ Gangue } & 50.4 & 13.4 & 12.7 \\
\hline \multicolumn{2}{|c|}{ Total } & 100.00 & 100.00 & 100.00 \\
\hline
\end{tabular}

\section{B. Reagents}

Analytical grade of reagents, $\mathrm{H}_{2} \mathrm{SO}_{4}, \mathrm{NaNO}_{3}$ and $\mathrm{NaCl}$ were used in the tests. Seawater was obtained from San Jorge Bay (Antofagasta). Seawater was filtered $(1 \mu \mathrm{m}$, sand quartz and polyethylene membrane). Discard brine from reverse osmosis process was obtained from desalination plant of Antofagasta. Table II shows the concentration of ions in the seawater and brine obtained by different analytical techniques (AAS, volumetric and gravimetric analysis, inductively coupled plasma atomic emission spectroscopy ICP-AES)

TABLE II

CHEMICAL ANALYSES OF SEAWATER AND BRINE (MG/L)

\begin{tabular}{|c|c|c|}
\hline Element & Seawater & Brine \\
\hline $\mathrm{Mg}^{2+}$ & 1256 & 2297 \\
\hline $\mathrm{Na}^{+}$ & 11250 & 19768 \\
\hline $\mathrm{K}^{+}$ & 401 & 746 \\
\hline $\mathrm{Cl}^{-}$ & 20289 & 36074 \\
\hline $\mathrm{SO}_{4}{ }^{2-}$ & 2758 & 5063 \\
\hline $\mathrm{NO}_{3}{ }^{-}$ & 2.40 & 6.40 \\
\hline
\end{tabular}

C. Procedure

Leaching tests by stirring used $1 \mathrm{~L}$ of jacketed glass reactors. A thermostatic bath controlled the temperature at 45 ${ }^{\circ} \mathrm{C}$. Mechanical stirring was providing at $400 \mathrm{rpm}$. Copper extraction was monitored over time to obtain kinetic curves. For 
this, solution samples of the tests were periodically taken for analysis of copper concentration by AAS. In addition, solid waste was analyzed by chemical and mineralogical analysis (AAS and optical microscopy).

In addition, pretreatment tests were performed with concentrate samples. When the pretreatment was used, the concentrate was conditioned. A sample of concentrate was placed on a plastic sheet and solid reagents were added: $23 \mathrm{~kg}$ of sodium nitrate/ton of solid sample and $12 \mathrm{~kg}$ of chloride/ton of solid sample. This mixture was homogenized and $17 \mathrm{~kg}$ of sulfuric acid/ton of solid sample was added. Finally, seawater was added to complete $15 \%$ moisture of the mixture. The conditioned sample was allowed at rest (20 days) in a plastic sheet at $25{ }^{\circ} \mathrm{C}$. When the resting time was reached, the solid sample was leached using $0.7 \mathrm{M}$ of sodium nitrate, $0.7 \mathrm{M}$ of sulfuric acid and seawater as solvent. The other test, called "repose in solution", considers that the conditioned sample was left in a reactor with leaching solution $(0.7 \mathrm{M}$ of sodium nitrate, $0.7 \mathrm{M}$ of sulfuric acid and seawater as solvent) for 20 days and then the stirring began.

The variables studied in this research were: concentrations of chloride, type of solvent, source of nitrate and pretreatment of the solid sample.

\section{RESULTS AND DISCUSSION}

Figures 1, 2 and 3 show the copper extraction in function of type of solvent used (water, seawater and brine from the reverse osmosis process) when different solid samples were used. In all cases, the water shows a lower copper extraction in comparison to use seawater or brine. This is due to chloride presence that improve the copper extraction from chalcopyrite.

When the concentrate is leached, seawater showed a better copper extraction than when brine was used. This could be due concentrate sample contain covellite and digenite, copper sulfides more soluble in chloride media than chalcopyrite. Better copper extractions were obtained when brine was used for the other tests, pure sample and low grade ore. In both cases, it is observed that the brine has better copper extraction results, mainly due to the greater presence of chloride in the system (36 $\mathrm{g} / \mathrm{L})$.

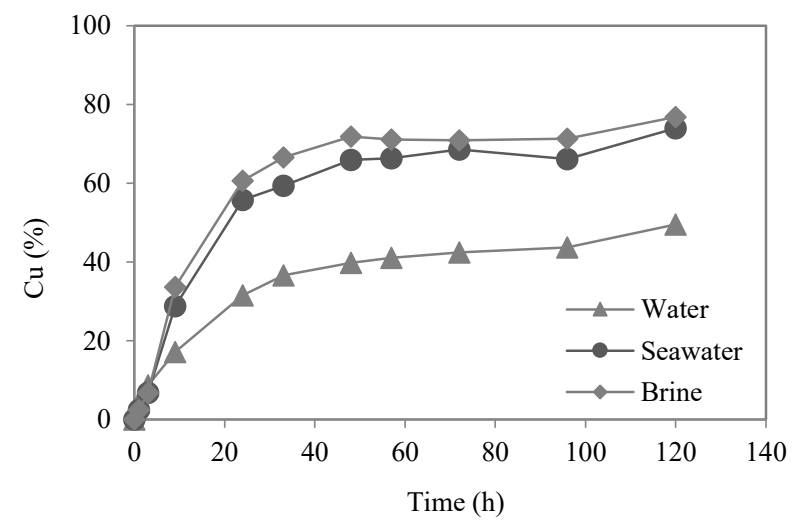

Fig. 1 Copper extraction (\%) vs. time (h) in function of solvent used: water, seawater and brine. (Experimental conditions: leaching by stirring, $45^{\circ}$
$\mathrm{C},\left[\mathrm{H}_{2} \mathrm{SO}_{4}\right]=\left[\mathrm{NaNO}_{3}\right]=0.5 \mathrm{M}, 100 \mathrm{~g}$ of ore $/ 1000 \mathrm{~mL}$ solution, 5 days of leaching, particle size under $150 \mu \mathrm{m}$, low grade ore $1.6 \% \mathrm{Cu}$ )

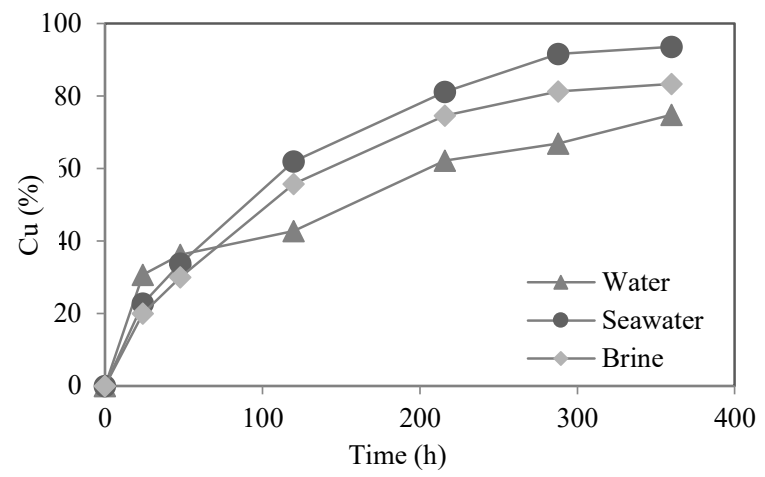

Fig. 2 Copper extraction (\%) vs. time (h) in function of solvent used: water, seawater and brine. (Experimental conditions: leaching by stirring, $45^{\circ}$ $\mathrm{C},\left[\mathrm{H}_{2} \mathrm{SO}_{4}\right]=\left[\mathrm{NaNO}_{3}\right]=0.7 \mathrm{M}, 50 \mathrm{~g}$ concentrate $/ 500 \mathrm{~mL}$ solution, 15 days of leaching, particle size under $150 \mu \mathrm{m}$, concentrate copper grade $12.9 \% \mathrm{Cu}$ )

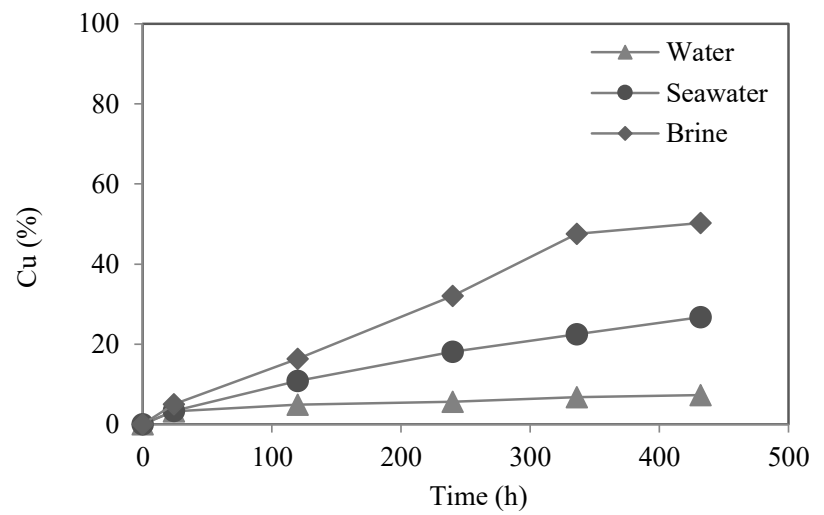

Fig. 3 Copper extraction (\%) vs. time (h) in function of solvent used: water, seawater and brine. (Experimental conditions: leaching by stirring, $45^{\circ}$

$\mathrm{C},\left[\mathrm{H}_{2} \mathrm{SO}_{4}\right]=\left[\mathrm{NaNO}_{3}\right]=0.7 \mathrm{M}, 1 \mathrm{~g}$ of ore $/ 500 \mathrm{~mL}$ solution , 18 days of

leaching, particle size under $150 \mu \mathrm{m}$, sample chalcopyrite grade $29.1 \% \mathrm{Cu}$ )

A maximum of $76.8 \%, 93.7$ and $50.3 \% \mathrm{Cu}$ were obtained by leaching of low grade ore, concentrate and pure sample, respectively.

Figures 4, 5 and 6 show the copper extraction in function of chloride concentration when different solid samples were used.

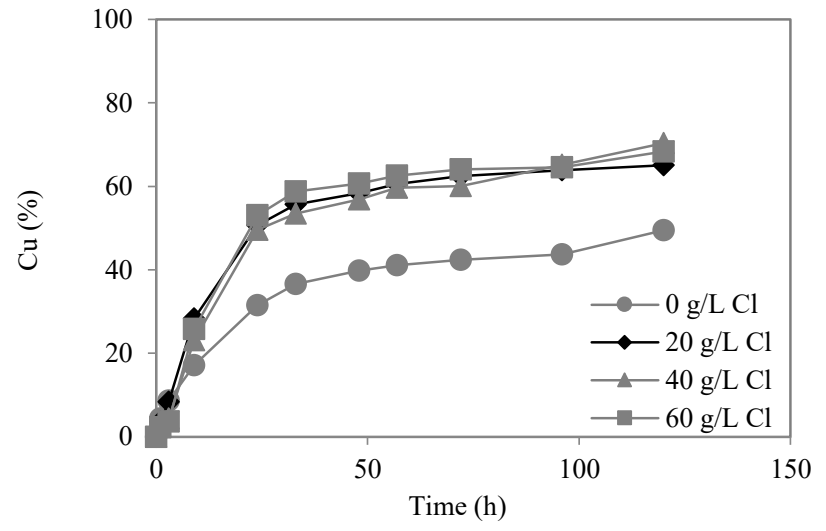


Fig. 4 Copper extraction (\%) vs. time (h) in function of chloride concentration: $0,20,40$ and $60 \mathrm{~g} / \mathrm{L}$. (Experimental conditions: leaching by stirring, $45^{\circ} \mathrm{C},\left[\mathrm{H}_{2} \mathrm{SO}_{4}\right]=\left[\mathrm{NaNO}_{3}\right]=0.5 \mathrm{M}$, water as solvent, $100 \mathrm{~g}$ of ore/1000 mL solution, 5 days of leaching, particle size under $150 \mu \mathrm{m}$, low grade ore $1.6 \% \mathrm{Cu}$ )

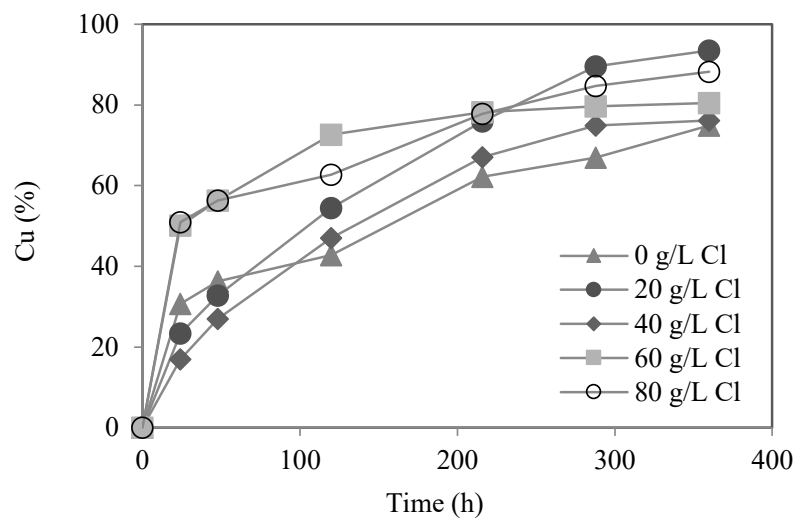

Fig. 5 Copper extraction (\%) vs. time (h) in function of chloride concentration: $0,20,40,60$ and $80 \mathrm{~g} / \mathrm{L}$. (Experimental conditions: leaching by stirring, $45^{\circ} \mathrm{C},\left[\mathrm{H}_{2} \mathrm{SO}_{4}\right]=\left[\mathrm{NaNO}_{3}\right]=0.7 \mathrm{M}$, water as solvent, $50 \mathrm{~g}$ concentrate $/ 500 \mathrm{~mL}$ solution , 15 days of leaching, particle size under $150 \mu \mathrm{m}$, concentrate copper grade $12.9 \% \mathrm{Cu}$ )

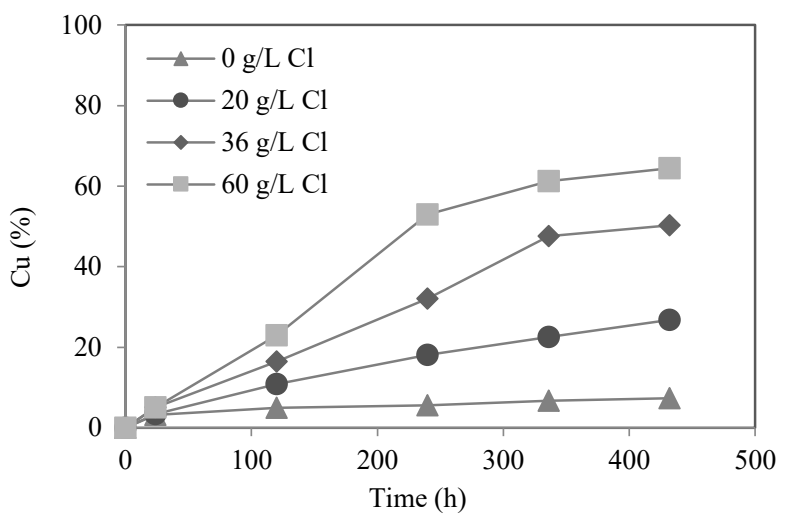

Fig. 6 Copper extraction (\%) vs. time (h) in function of chloride concentration: 0, 20,36 and $60 \mathrm{~g} / \mathrm{L}$. (Experimental conditions: leaching by stirring, $45^{\circ} \mathrm{C},\left[\mathrm{H}_{2} \mathrm{SO}_{4}\right]=\left[\mathrm{NaNO}_{3}\right]=0.7 \mathrm{M}$, water as solvent, $1 \mathrm{~g}$ of ore $/ 500$

$\mathrm{mL}$ solution, 18 days of leaching, particle size under $150 \mu \mathrm{m}$, sample chalcopyrite grade $29.1 \% \mathrm{Cu}$ )

Figure 4 shows that an increase in the concentration of chloride from 0 to $20 \mathrm{~g} / \mathrm{L}$, produces a $30 \%$ increase in copper extraction in comparison with chloride is not present in the media. Moreover, a slightly increase was observed when chloride concentration increases in the media over $20 \mathrm{~g} / \mathrm{L}$. It is appreciated that the presence of this ion is important, but that an excess does not have a greater influence on the conditions studied when low grade ore is used.

Figure 5 shows a similar behavior of the Figure 4. When $80 \mathrm{~g} / \mathrm{L}$ of chloride concentration was used, the copper extraction achieved was lesser than $20 \mathrm{~g} / \mathrm{L}$ of chloride was present in the media.

Figure 6 shows something different. In this case, the increase of chloride concentration produced an increase on copper extraction. Due to this results, the gangues or other mineralogical species influenced in the results showed in Figure 4 and 5.
A maximum of $70.3 \% \mathrm{Cu}\left(40 \mathrm{~g} \mathrm{Cl}^{-} / \mathrm{L}\right), 93.5 \mathrm{Cu}\left(20 \mathrm{~g} \mathrm{Cl}^{-} / \mathrm{L}\right)$, and $64.4 \% \mathrm{Cu}\left(60 \mathrm{~g} \mathrm{Cl}^{-} / \mathrm{L}\right)$, were obtained by leaching of low grade ore, concentrate and pure sample, respectively.

Figure 7 shows the copper extraction over time when comparing a test using analytical sodium nitrate and a discarding salt from the caliche process that contains $64 \%$ nitrate. It can be seen that both extraction curves are very similar to each other. This would verify that it is possible to use these salts in the process.

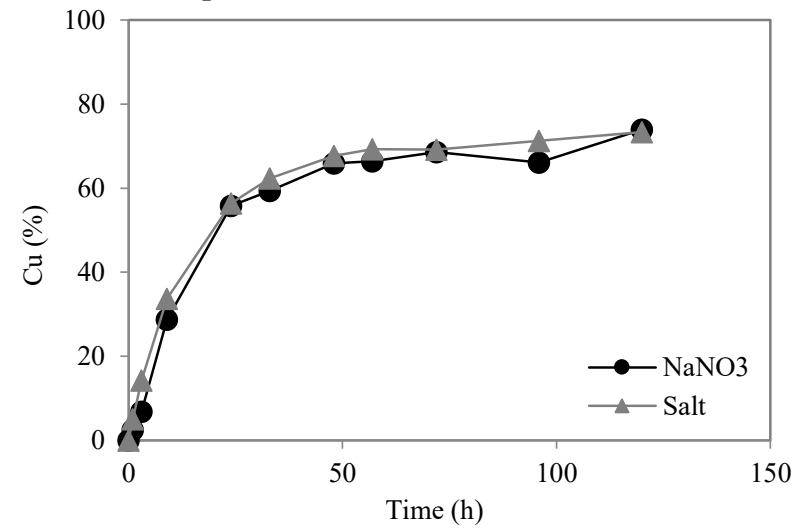

Fig. 7 Copper extraction (\%) vs. time (h) in function of nitrate source: analytical $\mathrm{NaNO}_{3}$ or industrial salt. (Experimental conditions: leaching by stirring, $45^{\circ} \mathrm{C},\left[\mathrm{H}_{2} \mathrm{SO}_{4}\right]=\left[\mathrm{NaNO}_{3}\right]=0.5 \mathrm{M}$, seawater as solvent, $100 \mathrm{~g}$ of ore/1000 mL solution, 5 days of leaching, particle size under $150 \mu \mathrm{m}$, low grade ore $1.6 \% \mathrm{Cu}$ )

Figure 8 shows the copper extraction over the time when a pretreatment and repose in solution were used in a concentrate sample. It can be seen that both treatments have a positive response to copper extraction, compared to the untreated system. By projecting the extraction curve of the test without pretreatment, the same extraction percentages could be achieved as the samples with pre-conditioning, but raising the costs, because the leaching process has been continuous. Case different from when there is a resting time where the expense would occur in a physical place where the solid treated leave for a certain time.

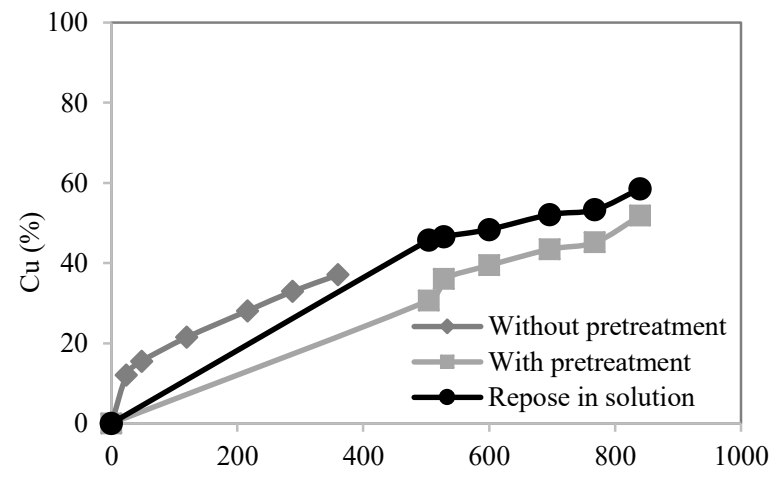

Time (h)

Fig. 8 Copper extraction (\%) vs. time (h) in function of pretreatment: without pretreatment (only leaching), with pretreatment and repose in solution. (Experimental conditions: leaching by stirring, $25^{\circ} \mathrm{C},\left[\mathrm{H}_{2} \mathrm{SO}_{4}\right]=$ $\left[\mathrm{NaNO}_{3}\right]=0.7 \mathrm{M}$, seawater as solvent, $50 \mathrm{~g}$ concentrate $/ 500 \mathrm{~mL}$ solution ,15 
days of leaching, particle size under $150 \mu \mathrm{m}$, concentrate copper grade $12.9 \%$

$\mathrm{Cu})$

\section{CONCLUSIONS}

The acid-nitrate-chloride system for leaching chalcopyrite has been studied as alternative to leach chalcopyrite ore using seawater or brine and salts of caliche industry. The results have shown that:

- This system produces satisfactory copper extractions, above $60 \%$ at atmospheric pressure and temperatures of $45^{\circ} \mathrm{C}$.

- Chloride ions are beneficial to chalcopyrite leaching, but in samples with gangues presence, the use of seawater or brines $(36 \mathrm{~g} / \mathrm{L})$ is enough to obtain satisfactoriness results of copper extractions at studied conditions in this research.

- Industrial salts and brine solutions (seawater and discard of reverse osmosis) have been used with satisfactory results. They could be alternatives of raw materials in the leaching process of chalcopyrite dissolution.

- A conditioning stage (pretreatment) was essential to accelerate the dissolution kinetics of copper in the systems studied because the majority of copper extraction is achieved in this step.

- A pretreatment step could be beneficious alternative to industrial scale due to the reduction of the energy consumption by a decrease of the irrigation time in heap leaching.

\section{ACKNOWLEDGMENT}

The authors thank ANID-Chile for financing this research through Fondecyt de Iniciación Project N¹1170179. Authors are also grateful of the Project ING2030 CORFO Code 16ENI2-71940.

\section{REFERENCES}

[1] Sernageomin, Anuario de la minería de Chile 2018, G.d.C. Ministerio de Minería, Editor. 2018: Santiago.

[2] Watling, H., Chalcopyrite hydrometallurgy at atmospheric pressure: 1. Review of acidic sulfate, sulfate-chloride and sulfate-nitrate process options. Hydrometallurgy, 2013. 140: p. 163-180.

[3] Watling, H., Chalcopyrite hydrometallurgy at atmospheric pressure: 2. Review of acidic chloride process options. Hydrometallurgy, 2014. 146: p. 96-110.

[4] Shiers, D., et al., Copper extraction from chalcopyrite: Comparison of three non-sulfate oxidants, hypochlorous acid, sodium chlorate and potassium nitrate, with ferric sulfate. Minerals Engineering, 2016. 85: p. 55-65.

[5] Habashi, F. Nitric acid in the hydrometallurgy of sulfides. in EPD Congress 1999. 1999.

[6] Sokić, M.D., B. Marković, and D. Živković, Kinetics of chalcopyrite leaching by sodium nitrate in sulphuric acid. Hydrometallurgy, 2009. 95(3): p. 273-279.

[7] Hernández, P.C., et al., Leaching of Chalcopyrite in Acidified Nitrate Using Seawater-Based Media. Minerals, 2018. 8(6): p. 238.

[8] Gok, O. and C.G. Anderson, Dissolution of low-grade chalcopyrite concentrate in acidified nitrite electrolyte. Hydrometallurgy, 2013. 134-135: p. $40-46$. 